\title{
Quantified Self in de huisartsenpraktijk
}

\section{Bijblijven 2015}

Dr. Martijn de Groot ${ }^{1}$, Drs. Bart Timmers ${ }^{2}$, Thea Kooiman $\mathrm{MSc}^{3}$, Dr. Miriam van Ittersum ${ }^{4}$ (The final publication is available at Springer via http://dx.doi.org/10.1007/s12414-015-0077-2)

\footnotetext{
${ }^{1}$ Medisch bioloog/senior onderzoeker, Lectoraat Healthy Ageing, Allied Health Care and Nursing en lectoraat New Business and ICT, Hanzehogeschool Groningen. Onderzoeksleider, Quantified Self Institute, Hanzehogeschool Groningen.

${ }^{2}$ Huisarts/huisartsopleider, Groepspraktijk Huisartsen Bergh, 's-Heerenberg.

3 Oefentherapeut/bewegingswetenschapper/promovenda, Lectoraat Healthy Ageing, Allied Health Care and Nursing, Hanzehogeschool Groningen.

${ }^{4}$ Fysiotherapeut/bewegingswetenschapper/hogeschooldocent, opleiding Fysiotherapie, Academie voor Gezondheidsstudies, Hanzehogeschool Groningen. Post-doc, Quantified Self Institute, Hanzehogeschool Groningen.
}

\section{Samenvatting}

Quantified Self staat voor de zelfmetende mens. Het aantal mensen dat met zelf gegeneerde gezondheidsgegevens het zorgproces binnenwandelt gaat de komende jaren groeien. Verschillende soorten activity trackers en gezondheidsapplicaties voor de smartphone maken het relatief eenvoudig om persoonlijke gegevens te verzamelen over beweging, voeding, slaap, hartslag, menstruatiecyclus, etc. Steeds vaker zullen patiënten dit soort data meenemen naar de huisarts. Het is daarom raadzaam kennis te nemen van wat er zoal aan zelfmeettechnologie beschikbaar is en hoe het is gesteld met de kwaliteit, toepasbaarheid of zelfs generaliseerbaarheid van de data. In dit artikel lichten we de achtergrond van Quantified Self toe, zetten we dit in een breder perspectief van technologische ontwikkelingen en zullen we iets zeggen over de zin en onzin van zelfmetingen, waarbij de focus zal liggen op Quantified Self met betrekking tot gezondheid en levensstijl. 


\section{Inleiding}

Het is voor consumenten de afgelopen jaren steeds makkelijker geworden om hun eigen gezondheidsdata te genereren [1]. Verschillende soorten activity trackers en gezondheidsapplicaties voor de smartphone maken het relatief eenvoudig om persoonlijke gegevens te verzamelen over beweging, voeding, slaap, hartslag, menstruatiecyclus, etc. Steeds vaker zullen patiënten dit soort data mee nemen naar de huisarts. En naar verwachting zal de huisarts ook steeds vaker de patiënt vragen om zelf gezondheidsinformatie te verzamelen, bijvoorbeeld in het kader van zelf management of met als doel klinische observaties te verrijken.

Wat is er allemaal beschikbaar aan zelfmeet apparatuur? Hoe goed zijn al die consumenten producten? Worden de patiënt en de huisarts hier nou beter van? In dit artikel lichten we de achtergrond van Quantified Self toe, zetten we dit in een breder perspectief van technologische ontwikkelingen en zullen we iets zeggen over de zin en onzin van zelfmetingen. Want grote kans dat u hier de komende jaren steeds vaker mee te maken zult krijgen...

\section{Quantified Self: Persoonlijke betekenis uit persoonlijke data.}

"Het meest persoonlijke is tegelijk het meest universele", zo opende Gary Wolf afgelopen juni de Quantified Self Conference 2015 in San Francisco. Hij is samen met Kevin Kelly de bedenker van Quantified Self (QS) en oprichter van QS labs, een organisatie die sinds 2007 een wereldwijd groeiende community begeleidt bij haar zoektocht naar zelfkennis door zelfmeting [2, 3]. Kelly en Wolf stellen dat getallen antwoord kunnen geven op moeilijk te beantwoorden (levens)vragen, maar ook kunnen zorgen voor het herkennen van patronen die voorheen onzichtbaar waren. Een nobel streven, maar het valt niet altijd mee om persoonlijke betekenis te halen uit persoonlijke data. Daarom zijn momenteel (zomer 2015) in 38 landen meer dan 50.000 community members actief in 204 verschillende Meetup groups waar zij elkaar ontmoeten om de dialoog aan te gaan over deze zoektocht. Bijna elke week is er wel ergens in de wereld een meetup. Daarnaast zijn er twee jaarlijkse wereldwijde conferenties, afwisselend in San Francisco en Amsterdam. 


\section{Sociale beweging}

Tijdens de conferenties en meetups staan ontmoetingen centraal. Makers en gebruikers van technologie voor zelfmeting spreken elkaar over de toegevoegde waarde van persoonlijke data op zelfkennis. Drie eenvoudige vragen zijn daarbij leidend: 'wat heb je gedaan, hoe heb je dat gedaan en wat heb je ervan geleerd'. Die laatste vraag is het belangrijkste. Mits goed verzameld is data objectief en staat diepere reflectie op eigen gedrag toe. Dit kan over van alles gaan; over het aantal en type films dat je kijkt, over waar en met wie je sociale contacten aangaat, over je lichaamsgewicht, over het aantal luiers dat je verschoond, enzovoort. Technologie maakt zelfmeten makkelijk en voor een breed publiek toegankelijk. Het gebruik van wearables is alleen geen doel op zich binnen de QS community, als de gegevens met pen en papier of zelfs in het hoofd verzameld kunnen worden, dan kan het ook al doelmatig zijn. Een aantrekkelijk aspect van de QS beweging is dat allerlei mensen betrokken zijn en niemand uitgesloten is. Van Olympische atleten tot mensen die strijden tegen de gevolgen van kanker; hackers, makers, kunstenaars, wetenschappers, etc. Oftewel feitelijk iedereen denkbaar die op zoek is naar zijn eigen antwoorden daar waar standaard oplossingen niet langer helpen of de reguliere dienst- of zorgverlening niet voldoet.

\section{Quantified Self Institute in Nederland}

In 2012 werd in samenwerking met QS Labs (San Francisco, USA) in Nederland het Quantified Self Institute opgericht bij de Hanzehogeschool Groningen. Het is een multidisciplinaire netwerkorganisatie die kennis over personalised digital health vertaald naar onderwijs- en onderzoeksprogramma's [4]. De focus ligt daarbij op de 'Big five for Healthy Life'; beweging, voeding, slaap, stress en sociale interactie. Dit zijn vijf thema's waarvan het aannemelijk is dat het handhaven van een goede balans bijdraagt aan het gezond opgroeien en gezond oud worden van individuen. In samenwerking met regionale en (inter)nationale partners worden onderzoeksprojecten uitgevoerd waarbij wordt gekeken naar accuratesse van zelfmeting, hoe en in welke mate dit effectief kan bijdragen aan het bevorderen van een gezonde leefstijl bij bijvoorbeeld werknemers of mensen met diabetes. 


\section{Wearables \& activity trackers}

Het grootste deel van deze zogenaamde self-tracking activiteiten vindt plaats op het gebied van leefstijl en gezondheid. Dat is tenslotte ook het meest persoonlijke dat we bezitten. We zullen ons in dit hoofdstuk beperken tot quantified self op het gebied van gezondheid.

Er is veel beschikbaar en het aantal sensoren dat je kunt gebruiken om een aspect van je lichaam of gedrag te meten groeit exponentieel. Meestal worden ze kortweg 'wearables' genoemd (naar 'wearable technology'). Een uitgebreide lijst is te vinden op de blogpost van Jeroen Cornelissen waar bijna duizend sensoren beschreven staan die geschikt zijn voor zelfmeten en voor gebruik in decentrale locaties zoals huisartsen, gezondheidscentra en huisartsenposten [5]. De meest populaire wearables zijn de activity trackers. Het zijn digitale versnellingsmeters die je om je pols of in je broekzak draagt en zo automisch bijhouden hoeveel je beweegt of slaapt (niet beweegt). De meest verkochte activity trackers zijn van het merk Fitbit Inc., een Amerikaans bedrijf dat er inmiddels zoveel geld mee heeft verdiend dat het in mei 2015 tot de Amerikaanse beurs toetrad.

\section{Hoe accuraat zijn activity trackers?}

Er komen langzaam steeds meer wetenschappelijke publicaties beschikbaar die iets zeggen over de accuratesse van technologie voor zelfmeting. Er is veel vraag naar kennis over validiteit en betrouwbaarheid en het wetenschappelijk onderzoek loopt een paar passen achter op de technologische vooruitgang. Afgelopen zomer verscheen er in het toonaangevende medische tijdschrift JAMA (Journal of the American Medical Association) een research letter waarin verslag werd gedaan van de accuratesse van een paar activity trackers en smartphone applicaties [6]. Het Quantified Self Institute deed samen met onderzoekers van het lectoraat Healthy Ageing, Allied Health Care and Nursing en van het Centrum voor Beweging en Onderzoek in Groningen onderzoek naar de validiteit en betrouwbaarheid van tien populaire activity trackers [7]. De volgende trackers werden onderzocht: de Fitbit Flex, Jawbone Up, Nike+ Fuelband SE, Misfit Shine, Withings Pulse, Fitbit Zip, Lumoback, Omron HJ-203, Yamax Digiwalker SW-200 and Moves applicatie (figuur 1). Deze 
trackers werden gekozen vanwege variatie in populariteit (met Fitbit, jawbone en Nike als populaire merken onder consumenten en de Digiwalker als veelgebruikte bewegingsmeter in onderzoek), prijsklasse, technologie ('eenvoudige' stappentellers of 2- of 3-assige accelerometers) en draagpositie (pols-gedragen voor de Fitbit Flex, Jawbone Up en Nike+ Fuelband, en centraal gedragen; op de heup, om de middel of in de broekzak, voor de overige trackers).

1

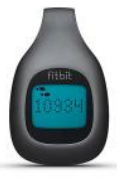

5

8

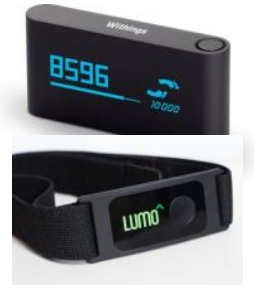

2

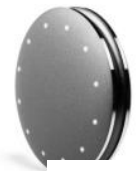

6

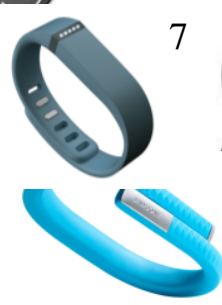

(1)

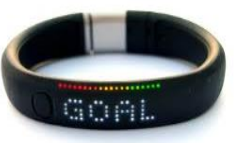

4
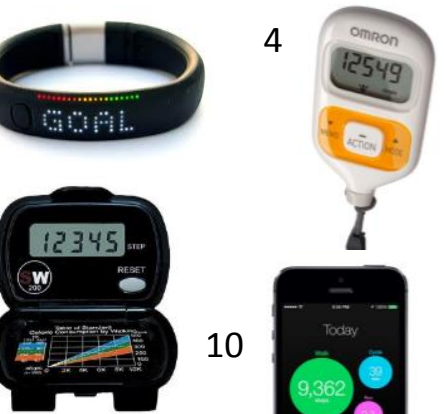

10

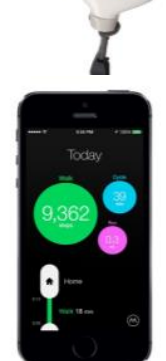

Figuur 1 Tien activity trackers die werden getoetst op hun accuratesse. 1= Fitbit Zip, 2= Misfit Shine, $3=$ Nike + Fuelband, $4=$ Omron Walking style III, $5=$ Withings Pulse, $6=$ Fitbit Flex, $7=$ Digiwalker SW200, 8 = Lumoback, 9 = Jawbone Up, $10=$ Moves app

De trackers werden onderzocht met twee verschillende methoden. In de labstudie droegen 33 proefpersonen de trackers tweemaal voor een half uur, terwijl zij liepen op de loopband op een gemiddelde loopsnelheid. Het Optogait systeem, welke het aantal stappen dat gezet werd precies kon meten, werd gebruikt als gouden standaard.

In de veldstudie droegen 56 proefpersonen de trackers tijdens één werkdag. Hierbij werd de ActivPAL, een goed gevalideerde accelerometer, gebruikt als gouden standaard.

Uit de resultaten kwam naar voren dat de Fitbit Flex, Jawbone Up, Misfit Shine, Withings Pulse, Fitbit Zip, Lumoback en Yamax Digiwalker SW-200 betrouwbare metingen lieten zien met een hoge test- 
hertest betrouwbaarheid. Van deze zeven trackers lieten vijf trackers ook een hoge validiteit zien, waarbij ze inwisselbaar waren met de gouden standaard. De validiteit van de Fitbit Flex, Digiwalker en Omron was voldoende. De Nike+Fuelband liet een duidelijke onderschatting zien van het aantal stappen, en de Moves app (geïnstalleerd op een Iphone) een overschatting.

In de veldstudie nam de validiteit over het algemeen af. Er kwam één duidelijke winnaar uit de bus: de Fitbit zip. Deze tracker liet een hoge overeenstemming met de gouden standaard zien. Ook de Misfit Shine en Lumoback lieten een redelijk hoge validiteit zien. De Fitbit Flex, Jawbone Up, Withings Pulse, Omron en Digiwalker lieten gemiddeld een afwijking van (ruim) onder de $10 \%$ zien, wat gezien wordt als acceptabele afwijking in 'free-living' omstandigheden. Echter, de individuele afwijkingen (beoordeeld via Bland-Altman plots) waren hoger voor deze trackers. De Nike+Fuelband gaf opnieuw een duidelijke onderschatting van het aantal stappen.

Samenvattend, kwam uit deze studie naar voren dat de betrouwbaarheid en validiteit van de Lumoback, Fitbit Flex, Jawbone UP, Misfit Shine, Withings Pulse, Fitbit Zip, and Digiwalker voldoende tot goed is. Deze trackers zijn geschikt voor consumenten gebruik en leefstijlprogramma's. De Fitbit zip liet de beste validiteit zien en is ook geschikt voor onderzoeksdoeleinden.

Deze resultaten zijn gelijk aan bevindingen uit andere studies, waarin de Fitbit Zip, Jawbone Up, Misfit Shine, Withings Pulse en Digiwalker ook een goede validiteit lieten zien. Ook de duidelijke onderschatting van het aantal stappen van de Nike+Fuelband kwam overeen met andere studies [6, $8,9]$.

\section{Welke activity tracker is nu geschikt voor uw patient?}

Ten eerste is het belangrijk om te realiseren dat voor individuele gebruikers de betrouwbaarheid van een tracker belangrijker is dan de validiteit, doordat patiënten vooral geïnteresseerd zijn in veranderingen in hun beweeggedrag [10]. Uiteraard moet een zelfmeter wel valide genoeg zijn, anders verliest zij geloofwaardigheid bij de eindgebruiker. Een relatief kleine (minder dan 5 á 10\%), standaard afwijking lijkt daarbij voor de individuele gebruiker nog acceptabel.

Ook is het goed om van te voren duidelijk te hebben welke activiteit precies gemeten zal gaan 
worden, zodat de beste draagpositie bepaald kan worden. Als een patiënt voornamelijk meer wil gaan fietsen, is een tracker die cyclische bewegingen kan meten en om de enkel gedragen wordt, het meest geschikt. Een voorbeeld van zo'n tracker is de MOOV. Er kan ook gekozen worden voor een app welke via GPS de fietsroute en snelheid bijhoudt (bijv. Strava, Runkeeper of Runtastic). Polsgedragen trackers kunnen geen fietsbewegingen meten, dus zijn voor mensen die het fietsen willen gaan opbouwen niet geschikt. Polsgedragen trackers of smartwatches hebben voor veel consumenten wel vaak de voorkeur, doordat deze meestal meerdere functies hebben (weergave van datum, tijd, display met real-time meetgegevens, verbinding met smartphone).

Een ander aspect dat zeker zal meewegen bij het aanbevelen van een activity tracker is de prijs. De Fitbit zip is als één van de geavanceerdere trackers met 50 euro de goedkoopste in onze studie. Nieuw uitgebrachte trackers van bijvoorbeeld Misfit en Jawbone (Misfit Flash, Jawbone move) zijn nog wat goedkoper verkrijgbaar. Smartwatches en activity trackers van merken als Garmin en Polar zijn weer wat duurder. Deze trackers hebben dan vaak ook een mooie, gebruikersvriendelijke interface en de bijbehorende apps hebben veel ingebouwde functies als doelen instellen en geautomatiseerde motiverende berichten. Stappentellers als Omron en Digiwalker zijn het goedkoopst (rond de 20 euro), en direct in gebruik te nemen zonder registratie via internet of installatie van bijbehorende app. Hierdoor zijn deze trackers wellicht voor de oudere patiënt meer geschikt.

\section{Smartphone als wearable met een keur aan gezondheidsapplicaties}

Naast alle wearables is de smartphone bij uitstek een stuk technologie wat zich leent voor het verzamelen van persoonlijke data. Nederland kent een groot aantal smartphone (> 10 miljoen) en tablet (>8 miljoen) gebruikers [11]. Al in 2014 passeerde alleen de app store van Apple de magische grens van 1 miljoen applicaties. Naar schatting 20\% daarvan betreft applicaties op het gebied van gezondheid. Een niet uitputtende selectie is te vinden op de website van myhealthapps (http://myhealthapps.net/). Een aantal populaire apps op het gebied van voedings, beweging, slaap en stress staan in tabel 1 weergegeven. 
In Nederland is een aantal pogingen gedaan een overzicht te maken van medische apps. Het meest complete overzicht is te vinden op de website van de digitale zorggids (www.digitalezorggids.nl) waar circa 10.000 apps voor zorgprofessionals en consumenten op staan. In 2013 kondigden KNMG en VVAA aan een database met medische apps te zullen starten, maar die is er niet gekomen. Vanuit Artsennet en MedicalPHIT groeit sinds 2012 een database nav het initiatief tot het uitreiken van de "Health App Award". Naast inbreng van de jury kunnen zorgverleners zelf ook apps aandragen. Artsennet bestaat sinds juni 2015 niet meer, maar het initiatief van de Health App Award is overgedragen en wordt nu naast MedicalPHIT mede georganiseerd door VVAA en Nictiz. Op Mobile Doctors worden reviews van apps en wearables geplaatst zodat het idee van die database alsnog vorm aan het krijgen is. De KNMG heeft aangekondigt dit najaar een richtlijn te starten over hoe om te gaan met medische apps. Een belangrijke focus in de richtlijn is het helpen van artsen bij het inschatten van de betrouwbaarheid en de kwaliteit van medische apps.

Tabel 1 Een aantal populaire apps op het gebied van voeding, beweging, slaap en stress. Bron Quantified Self Institute (www.qsinstitute.org), big five for healthy life apps.

MyFitnessPal
Wat ligt er op mijn
Bord?

\section{Waar blijft toch dat keurmerk voor apps?}

Er is niet alleen in Nederland maar ook daarbuiten behoefte aan iets van een keurmerk voor applicaties dat voor medische doeleinden gebruikt kan worden. Met name artsen zijn gewend aan keurmerken en "evidence" en zijn daardoor nog enigszins onzeker over welke apps en wearables aan 
te bevelen zijn. Het NHG is bezig geweest met het ontwikkelen van een keurmerk voor apps en wearables, maar heeft uiteindelijk besloten dat dit geen haalbare kaart was. Wel wordt ingestoken op het verzamelen van ervaringen van zowel zorgconsumenten/patiënten en (huis)artsen. Verder heeft de KNMG besloten om in de loop van 2015 ook te proberen een keurmerk voor apps te gaan ontwikkelen. Een laatste ontwikkeling op dit gebied mag genoemd worden, het "applab" van senior onderzoeker Dr. Jaap Trappenburg van het UMCU. Ook hier wordt geprobeerd apps te ontwikkelen die voldoen aan de stand van de wetenschap. Het is dus niet zozeer een keurmerk, maar een poging om nieuwe apps te ontwikkelen die gestoeld zijn op wetenschappelijke inzichten en daar ook aan getoetst kunnen worden.

Een van de redenen waarom het ontwikkelen van een keurmerk zo moeilijk is, is dat door de snelle ontwikkelingen op ICT gebied veel initiatieven voortdurend door de actualiteiten worden ingehaald. Een app die doorontwikkeld wordt en voorzien van een serieuze update, kan daardoor ineens een essentieel andere app zijn. Zo heeft een keurmerk maar een heel beperkte houdbaarheid. In Amerika is een grote organisatie, Happtique, na enkele jaren noodgedwongen gestopt met hun keuringen. Het kostte enorm veel energie om een gedegen uitspraak tot keurmerk om te vormen en na 2 jaar bleek dat het nog maar voor 2 apps lukte!

Apple introduceerde kortgeleden de Apple watch. Deze wearable opent weer een hele nieuwe wereld aan mogelijkheden. Zorginstanties en haar controlerende organen kunnen het tempo van deze ontwikkelingen simpelweg niet bijbenen met regelgeving en richtlijnen. Toezichthouders en zorginstanties zullen anders moeten leren denken. Bijvoorbeeld door meer samen te werken met Communities of Practice; groepen van (vroege) gebruikers die de technologische trends op de voet volgen en kunnen helpen bij een eerste schifting van kaf en koren. Of door nauwer samen te werken met kennisinstellingen die voorop lopen bij het dessimineren van technologische innovaties.

\section{Quantified Self in de spreekkamer}

De huisarts krijgt nu al vragen over wearables en apps. Een kleine survey (415 deelnemers) van Medpanel in de USA geeft al wat inzicht [12]. Circa 15\% van de patiënten sneden het onderwerp 
tijdens een consult aan. Circa 8 op de 10 huisartsen gaf aan het afgelopen half jaar met $1 \%$ van de patiënten te hebben gesproken over wearables en apps. Het is nog niet veel, maar wel een groeiende trend. Meestal gaat het over wat er zo al beschikbaar is en of het toepasbaar is voor de patiënt en huisarts. Huisartsen kennen dit principe al, waar het gaat om zelfmetingen met betrekking tot bloeddrukmetingen. De draadloze bloeddrukmeter van Withings (aanschafprijs ca 130 Euro) is al sinds 2011 door de FDA goedgekeurd voor thuisgebruik. Het kan een goed alternatief zijn voor de 24uurs meter, bijvoorbeeld wanneer deze niet gelijk voorhanden is. De patient die zelf een bloeddrukmeter aanschaft is bovendien vaak meer betrokken bij het monitoren. Het is dan ook niet voor niets dat in de NHG standaard Cardiovasculair Risicomanagement al aandacht wordt besteed, naast de 24-uursmeting, aan de zelfmetende patient [13]. Er wordt dan wel een lagere grenswaarde ( $<135 \mathrm{mmHg}$ ) gehanteerd voor (milde) hypertensie.

De huisarts van nu wordt door deze ontwikkeling ook nog met andere problemen geconfronteerd. Want als de patient zijn data wil delen, waar moeten die dan verwerkt worden? Voor de huisarts is het HIS of in sommige gevallen het KIS de plaats waar gegevens verwerkt worden. Maar er zijn nog maar weinig mogelijkheden om de gegenereerde en aangeleverde data ook daadwerkelijk al in te lezen. Toch zal daar snel verandering in gaan komen. Los van het inlezen van die data zal een volgende uitdaging ook nog zijn om de continue aanvoer van nieuwe data zodanig te stroomlijnen dat het ook betekenisvol gaat zijn. Met andere woorden: Welk dashboard gaat de data in een leesbare vorm presenteren, hoe houden we grip op wat er binnen komt en gaat de software ook meedenken over de interpretatie van al die data?

Zorgroep Zorroo in Oosterhout voorziet patiënten al met een Fitbit, en stuurt de daaruit voortkomende data daadwerkelijk via Edifact-berichten naar het KIS. Op die manier wordt geprobeerd om de leefstijl, zo belangrijk bij veel chronische aandoeningen, te monitoren en de zelfgegenereerde data ook te betrekken bij de behandeling.

Een aantal HIS-sen is al bezig met het ontwikkelen van een patientenportaal, waar niet alleen gegevens uitgelezen kunnen worden, maar ook ingelezen. Zo heeft CGM huisarts (voorheen Mira) nu een patientenportaal waar de patiënt een aantal data zelf in kan voeren. Vooralsnog is dat aantal zeer beperkt (glucose, lengte en gewicht) maar het begin is er. En het is toe te juichen dat er op zijn 
minst enig bewustzijn is met betrekking tot de richting waarin de gezondheidszorg zich beweegt: De patiënt gaat zijn rol in het zorgproces geleidelijk steeds meer zelf invullen, en is dat eigenlijk niet heel erg logisch?

\section{Voordelen van het kunnen delen van je persoonlijke data}

Quantified Self start vanuit de persoonlijke motivatie om iets te weten over jezelf of je leefomstandigheden; je verzamelt persoonlijke data voor en door jezelf. Je bepaalt zelf op welke manier je dat doet en geeft hier op je eigen wijze betekenis aan. Omdat het gaat om digitale data is het relatief eenvoudig om de zelf gegeneerde gezondheidsdata te delen met vrienden, familie of zorgverleners. Een reden om data (digitaal) te delen met anderen kan zijn dat het motiveert om een doel dat je voor jezelf hebt gesteld te halen. Denk aan 'likes' op Facebook als je daar gepost hebt dat je zojuist een wandeling van 15 kilometer hebt gedaan. Ook kan een patiënt op soortgelijke wijze beslissen om zelfmetingen te laten zien aan zijn huisarts, om deze een indruk te geven van persoonlijke patronen in bepaalde gezondheids- of leefstijlkarakteristieken (bijvoorbeeld beweging of slaap). Hiermee krijgt de huisarts een breder beeld van de factoren die mogelijk een rol spelen bij de klachten waarvoor de patiënt bij hem / haar komt. Dit kan ondersteunend zijn in het diagnostisch proces en mogelijk leiden tot beter bij de individu passende behandelvoorstellen.

Het delen van persoonlijke data met anderen kan ook op een andere manier meerwaarde opleveren, zeker als andere self-trackers dat ook doen. Door meerdere individuen verzamelde persoonlijke data bij elkaar levert voor iedere self-tracker veel extra informatie op, bijvoorbeeld zoals gebeurt in de online community "Patients Like Me", waar het door de patiënten zelf delen van ervaringen over symptomen, behandelingen en bijwerkingen lijdt tot verrijkte informatie voor de individuele community-deelnemer. Je zou kunnen zeggen dat de Quantified Self in groepsvorm transformeert tot Quantified Us (figuur 2); gezamenlijke persoonlijke data die van waarde is voor de deelnemende individuen [14]. 


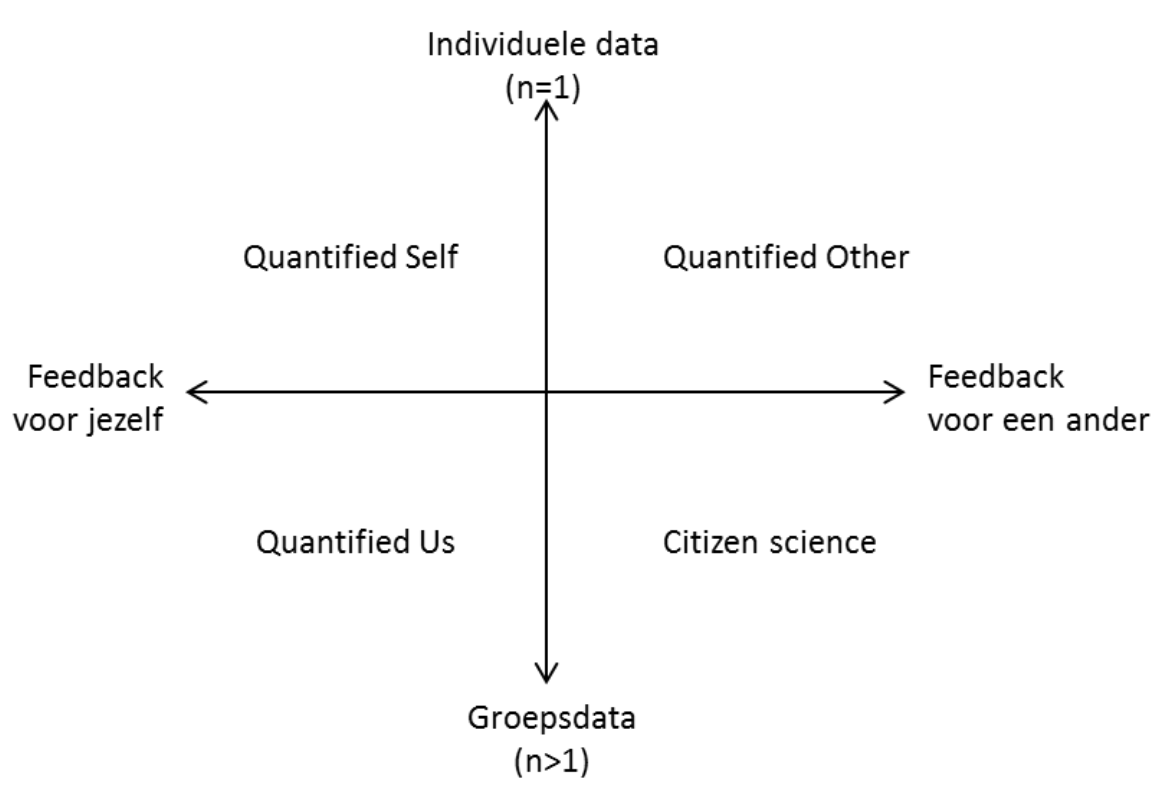

Figuur 2. Motief voor zelfmetingen uitgezet tegen met wie je de data deelt. Op eigen initiatief data verzamelen voor jezelf om eventueel te delen met vrienden/familie/coach (quantified self). Data delen met een groep van peers om zelf meer te leren van de data en andere ervan te laten leren (quantified us). Data verzamelen omdat iemand anders je vraagt dit te doen waar je zelf wat aan zou kunnen hebben (quantified other) of data verzamelen omdat iemand je dit vraagt zonder dat dit een eigenbelang dient (citizen science). Bron: http://www.digitalezorggids.n//blog/quantified-selfquantified-us-quantified-other.

\section{Self monitoring of surveillance?}

Zelfmeting als middel om te komen tot verandering/verbetering van je eigen gezondheid of prestaties is op zichzelf niet nieuw. Het is ook niet nieuw dat het delen van je prestaties met anderen kunnen helpen om gemotiveerd met je gedrag(sverandering) bezig te zijn. Toch zijn deze vormen van persuasive technology geen heilige graal om te komen tot positieve gedragsveranderingen. Daarvoor is menselijk gedrag te complex. Het delen van persoonlijke data kan zelfs de motivatie ondermijnen, bijvoorbeeld wanneer je in competitieverband data deelt en vaak verliest terwijl je daar niet tegen kunt of last krijgt van verhoogde stress door al dat zelfmeten en/of delen van data. Bovendien is de 
scheidslijn van persuasive technology naar een vorm van surveillance of 'big brother is watching you' vrij dun.

De discussie die hierbij zeker gevoerd moet worden is die van het data-eigenaarschap en veiligheid. Vragen als: 'Wie heeft controle over de gegevens die ik verzamel?', 'Wie heeft toegang tot de gegevens?', 'Wat kunnen anderen, indien zij toegang hebben, met de data?, Kan ik mijn eigen data definitief verwijderen?' zijn hier essentieel. Fabrikanten van wearables gebruiken de door hun klanten verzamelde data ook. De disclaimers van twee grote firma's (Fitbit en Withings) geven aan dat zij de data gebruiken om hun producten te verbeteren en dat ze big data geanonimiseerd aan derde partijen mogen doorverkopen. Dat hoeft allemaal niet zo'n probleem te zijn, maar het is niet altijd duidelijk hoe het zit.

Veel mensen worden in het bijzonder zenuwachtig als ze bedenken dat zorgverzekeraars mee kunnen kijken. Als je gezond gedrag vertoont is dat niet zo'n probleem, sterker nog, dan zou je zelf de voordelen kunnen zien bij een 'pay as you drive' constructie waarbij je voordelen geniet bij aantoonbaar (gemeten) gezond gedrag . Zorgverzekeraars zoals Menzis experimenteren momenteel met een puntensysteem voor zelfgemeten positieve gedragsverandering op het gebied van gezonde leefstijl. Hier is op zich niets mis mee, zolang volstrekt transparant blijft wat er met alle gegevens gebeurd. Uiteindelijk wil niemand, zorgverzekaars incluis, een stelsel waarbij iedereen systematisch gecontroleerd en bemeten wordt, zonder dat daarbij de meerwaarde ontegenzeggelijk vaststaat en de privacy van de individuele cliënt gewaarborgd is. Er zou namelijk een stigmatiserend effect uitgaan. Mensen die niet bereid zijn om hun zelfgegeneerde gezondheidsdata te delen zouden iets te verbergen kunnen hebben. Er liggen allerlei dwangmatige oplossingen op de loer zoals het verplichten van zelfmetingen en/of het delen van persoonlijke data. Dit staat haaks op vrijheid die we in Nederland zo hoog in het vaandel hebben.

\section{Alles is data}

Onder andere door self-tracking groeit de hoeveelheid data die opgeslagen wordt exponentieel. Niet alleen de opslag van deze zogenaamde Big data is een uitdaging. Ook het analyseren van de data 
speelt een steeds grotere rol. Hoe meer gegevens verzameld worden, hoe beter relaties gelegd kunnen worden en hoe meer informatie dit oplevert. In het klein geldt dit voor de individuele patiënt die op basis van zijn zelfmeet-gegevens mogelijk betere keuzes kan maken voor een gezonde leefstijl. Een voorbeeld uit de spreekkamer betreft een patient bekend met overgewicht, die de huisarts plots met een gezond gewicht op zijn spreekuur zag. Daarbij gaf hij aan dat niet de dietiste hem geholpen had, maar het gebruik van een voedingsapp (MyFitnesspal). Het gebruik gedurende maanden had niet alleen geleid tot fors gewichtsverlies, maar tot een permanent inzicht in het voedingspatroon, waar het een goede balans tussen inspanning en intake betreft.

In het groot geldt het dat de big data kansen biedt om op een geheel nieuwe manier Public Health Research te bedrijven. Het is niet voor niets dat Apple de Research kit lanceerde. Binnen enkele weken hadden onderzoekers via de Research kit duizenden deelnemers die bereid waren gezondheidsinformatie te delen voor onderzoek. Daar kleven natuurlijk ook allerlei nadelen aan. Dataverzamelen is lastiger te controleren en fraudegevoeliger. Bovendien worden gebruikers zonder smartphone uitgesloten en is snel sprake van een oververtegenwoordiging van mensen uit een hogere sociaal economische klasse. Niettemin illustreert Apple's Researchkit wel de potentie van de smartphone als instrument voor het verzamelen en gezondheidsgegevens en opent het een nieuwe dimensie voor het doen van Public Health Research.

\section{Personalised Health}

Zelf gegeneraliseerde gezondheidsdata zoals van lichaamsbeweging, slaap, stress en / of voeding over een langere periode kunnen het persoonlijke patiëntendossier verrijken. De huisarts vraagt nu in veel gevallen hier ook al naar, maar het blijft dan bij een grofmazige indruk op basis van de perceptie van de patiënt of in het beste geval gevat in de vorm van antwoorden op een (valide) vragenlijst. De huisarts zou met de patiënt op basis van deze rijke en objectievere informatie mogelijk betere, op de individu afgestemde behandelplannen kunnen opstellen. Een voorbeeld is dat uit onderzoek is gebleken dat het analyseren van het gebruik van de mobiele telefoon kan voorspellen wanneer voor een depressie kwetsbare personen ook daadwerkelijk depressief beginnen te raken. 
Men combineert daarbij zaken als het aantal telefoontjes, het aantal keren dat de telefoon uit de zak wordt gehaald, maar ook het zoeken op internet en de typsnelheid. Dat er nog geen harde evidence is voor bovenstaande opmerkingen heeft veel te maken met het feit dat het lastig is of simpelweg tijdrovend is om deze gepersonaliseerde aanpak te gieten in de vorm van een Randomized Clinical Trial. Er is dan ook in toemende mate interesse voor het Single Subject Design ( $n=1$ onderzoek). Deze onderzoeksvorm staat kleinere onderzoekspopulaties toe, omdat de statistische power wordt ontleent aan de grote hoeveelheid data per individu, in plaats van steekproefomvang zoals bij een $\mathrm{RCT}$. Deze manier van onderzoek doen is echter nog niet gangbaar, kent zo ook zijn eigen beperkingen en het ontbreekt doorgaans bij zorgverleners en onderzoekers aan kennis over deze onderzoeksvorm. Het is dan ook aan te bevelen dat in het (para)medisch en verpleegkundig onderwijs hier aandacht aan besteed wordt [15].

\section{Quantified Self is een onderdeel van een grotere verandering}

Technologische ontwikkelingen zijn in de afgelopen jaren sterk bepalend geweest voor onze economie. We leven bovendien in een periode waarin veranderingen door technologie exponentioneel snel gaan. Er ontstaan nieuwe manieren van zakendoen; denk aan Uber dat de taxiwereld op zijn kop zet, en Airbnb verandert de hotelwereld. De muziekindustrie heeft met de digitalisering al meerdere grote veranderingen moeten doorstaan om overeind te blijven en mee te gaan met de mogelijkheden en de wensen van de klant. Ook de retail merkt de gevolgen van internet en technologie. Volgens het rapport Hightech meets business dat het ING Economisch Bureau afgelopen juni (2015) uitbracht ter gelegenheid van de Dutch Technology Week zullen technologische doorbraken (en ook hier worden sensoren, Internet of Things en Big Data genoemd) op korte termijn vooral de industrie, de automotive èn de gezondheidszorg sectoren beïnvloeden [16].

Zelfmetingen heeft als perspectief om consument gedreven innovaties in de zorg toe te staan. De implementatie is echter uitermate complex. Er zijn naast de zorgvrager, zorgverlener en zorgverzekeraar nog veel meer stakeholders die opereren in een sterk veranderend klimaat van economische, sociale en politieke belangen. De roep om zelfmanagement en autonomie is niet alleen 
een democratisering van de zorg, maar ook het gevolg van bezuinigingen en tekorten.

Quantified Self als onderdeel van een grotere beweging draagt bij aan de paradigmaverschuiving richting een preventief en gepersonaliseerd gezondheidsmodel met een hogere mate van participatie door patiënten via data verzamelingstechnieken. Daarvoor is wel nodig dat er vanuit de zorg handreikingen worden gedaan richting deze beweging. Bijvoorbeeld daar waar het gaat om een koppeling tussen zelfgegeneerde gezondheidsdata en het HIS of de bereidheid om gezondheidsdata met de patiënt te bespreken.

\section{De dag voor morgen...}

Quantified Self is geen hype. Naar alle waarschijnlijkheid zal het nog zo'n 5 tot 10 jaar duren voordat het breed geaccepteerd zal zijn met grote toepassingsmogelijkheden en heldere relevantie. In de Gartner Cycle voor technologie (www.gartner.com) zien we meer technologische ontwikkelingen die van belang zijn voor de zorg. Gebaseerd op de ideeën van Dr. Eric Topol (auteur van de baanbrekende boeken "The Creative Destruction of Medicine: How the Digital Revolution Will Create Better Health Care" en "The patient will see you now") ontwikkelde Paul Sonnier het concept Digital Health. Dit is een veelomvattend begrip - waaronder o.a. mobile health (mHealth), eHealth, Telemedicine, Connected Health, Big Data, Quantified Self, Gamification, Precision and Personalized Medicine, Health 2.0 vallen - dat de bredere technologische revolutie in de gezondheidszorg beschrijft. Dit behelst razendsnelle ontwikkelingen op het gebied van draadloze apparatuur, sensoren (hardware), sensortechnologie (software), microprocessors, het internet, kennis en mogelijkheden rondom persoonlijke genetische informatie, sociale netwerken, mobiele netwerken, en gezondheids IT. Al deze ontwikkelingen zullen de gezondheidszorg beïnvloeden. Paul Sonnier geeft in een zeer aan te bevelen linked-in groep en op zijn website overzichten en samenvattingen van het laatste nieuws ten aanzien van ontwikkelde apps en devices, patenten, start-ups en evenementen op het gebied van technologie in de gezondheidszorg / Digital Health (www.storyofdigitalhealth.com). Handig om te weten en om te volgen zodat u van de laatste ontwikkelingen op dit gebied kunt bijblijven. 


\section{Referenties}

1. De Groot M, Timmers B, den Braber M: De zelfmetende mens. Medisch Contact 2014 (Aug): 1618-1620

2. Wolf, G. Data driven life New York Times Magazine 28 april 2010 www.nytimes.com/2010/05/02/magazine/02self-measurement-t.html

3. www.quantifiedself.com

4. www.qsinstitute.org

5. Cornelissen, J. Zorg en thuis technologie: http://ic25.blogspot.nl/2011/12/diagnose-apparatuur-voor-zelfmetenen.html

6. Case MA, Burwick HA, Volpp KG, Patel MS: Accuracy of smartphone applications and wearable devices for tracking physical activity data. JAMA 2015, 313(6):625-626.

7. Kooiman TJM, Dontje ML, Sprenger SR, Krijnen WP, van der Schans CP, de Groot M: Reliability and Validity of ten consumer activity trackers BMC Sports science, Medicine and Rehabilitation 2015.

8. Ferguson T, Rowlands AV, Olds T, Maher C: The validity of consumer-level, activity monitors in healthy adults worn in free-living conditions: a cross-sectional study. Int J Behav Nutr Phys Act 2015, 12:42-015-0201-9.

9. Lee JM, Kim Y, Welk GJ: Validity of consumer-based physical activity monitors. Med Sci Sports Exerc 2014, 46(9):1840-1848.

10. Dontje ML, de Groot M, Lengton RR, van der Schans, Cees P, Krijnen WP: Measuring steps with the Fitbit activity tracker: an inter-device reliability study. J Med Eng Technol 2015, 39(5):286-290.

11. http://www.gfk.com/nl/news-and-events/press-room/press-releases/paginas/evenveel-nederlanders-met-tabletals-vaste-computer.aspx

12. http://mobihealthnews.com/44828/small-survey-most-physicians-discuss-apps-wearables-with-patients/

13. Protocol Thuisbloeddrukmeting (2013) Nederlands Huisartsen Genootschap

14. de Groot M: Quantified Self, Quantified Us, Quantified Other. Digitale Zorggids 2014 http://www.digitalezorggids.nl/blog/quantified-self-quantified-us-quantified-other

15. de Groot M, van der Wouden JM, van Hell EA, Nieweg MB. Evidence-based practice for individuals or groups: let's make a difference. Perspectives on medical education 2013; 2(4):216-221

16. Erich M, Blom M (ING Economisch Bureau): High tech meets business, De economische impact van technologie voor sectoren, organisaties en mensen. Juni 2015. https://www.ing.nl/media/ING EBZ Hightech-meetsbusiness tcm162-86486.pdf 